\title{
Lo narrativo antropológico Apuntes sobre el rol de lo empírico en la construcción textual
}

Mariana Sirimarco

Universidad de Buenos Aires, Ciudad A. de Buenos Aires, Argentina

CONICET, Ciudad A. de Buenos Aires, Argentina

Correo electrónico: maikenas@yahoo.com.ar
Recibido:

6 de febrero de 2019

Aceptado:

19 de abril de 2019

doi: 10.34096/runa.v40i1.5545

\section{Resumen}

Construir un texto etnográfico implica, entre otras cosas, resolver hábilmente la inscripción de lo empírico en lo textual. Este trabajo es un intento por enfatizar esta vinculación, para demostrar que etnografía y narración son términos coimplicados. Se trata, así, de desmitificar la incompetencia de lo narrativo en el desarrollo de nuestro oficio, y de abogar por una escritura académica que reposicione la experiencia empírica analítica en el centro del proyecto antropológico.

\section{The anthropological narrative. Notes about the role of the empirical in the ethnographic text}

\begin{abstract}
Producing an ethnographic text implies -among other things- to skilfully solve the inscription of the empirical record in the text. This paper is an attempt to emphasize this connection, probing that ethnography and narrative are co-implicated terms. It is also an effort to demythologize the incompetence of narrativity in the development of our profession and to advocate for an academic writing that could reposition the empirical and analytical experience in the centre of the anthropological project.
\end{abstract}

\section{Palabras clave}

Antropología; Narratividad; Etnografía; Empiria; Texto etnográfico

\section{Key words}

Anthropology; Narrative; Ethnography; Empirical record; Ethnographic text 


\section{A narrativa antropológica. Notas sobre o papel do empírico na construção textual}

\section{Resumo}

Palavras-chave

Antropologia; Narratividade; Etnografia; Empiria; Texto etnográfico
1. No es objetivo de este trabajo contestar la afirmación lanzada por Geertz, sino tomarla como punto de partida para el desarrollo de otra discusión. Para un análisis de todas las aptitudes sobre las que se monta el trabajo del antropólogo, ver Cardoso de Oliveira (2000).

2. A lo largo de este texto utilizare las categorías "etnográfica" y "antropológica" como equivalentes, siempre que aluda a la escritura realizada por antropólogos. Hago esta aclaración porque entiendo que la etnografía como método puede ser extensiva a varias ciencias sociales, pero que es $\sin$ embargo, en el ámbito de la antropología donde la etnografía no solo implica un método sino una reflexión metodológica. Es a parti de esta confluencia que las planteo como equivalentes.

3. Si centro mi análisis únicamente en el discurso escrito es porque este es el recurso mayormente utilizado, en el ámbito local, para la construcción de conocimiento antropológico. Este énfasis no invalida la existencia y pertinencia de otros registros.
A construção de um texto etnográfico supõe, entre outras coisas, resolver com habilidade a inscrição do empírico no textual. Este trabalho é uma tentativa de enfatizar essa relação, mostrando que etnografia e narração são termos coimplicados. Trata se de desmistificar a incompetência do narrativo no desenvolvimento do nosso ofício, e advogar en favor de uma escrita acadêmica que reposicione a experiência empírica analítica no centro do projeto antropológico.

En una cita famosa, una y mil veces recuperada, Clifford Geertz (1986) sostuvo que lo que hacemos los antropólogos es escribir. La tesis fue contestada, de manera mayormente impugnatoria, sacando a relucir las muchas otras cosas que los antropólogos también hacemos, "antes y después de la escritura" (Reynoso, 1991, p. 55). Si lo que existe antes y después es - se supone, y para decirlo de modo resumido - aquello que se ha convertido en la tarjeta de presentación de nuestra disciplina - el trabajo de campo- ${ }_{1}^{1}$ las respuestas a la provocación de Geertz no hicieron más que levantar la polvareda de un debate que pareció convalidar ambas instancias como empresas disociadas. Sabemos, por el contrario, que trabajo de campo y escritura son tareas en continuidad, en tanto el primero origina una oralidad que suele inscribirse luego bajo formas discursivas. La hechura de la etnografía está indisolublemente ligada al trabajo cotidiano de escribir, pues la textualización -y no es esta una frase en redondo - es el nudo central de toda empresa etnográfica (Marcus, 1991; Clifford y Marcus, en Sharman, 2007).

Esta ligazón indisoluble entre etnografía y escritura se encuentra en el origen mismo del desarrollo disciplinar. Después de todo, una etnografía es, en su sentido etimológico, la escritura acerca de una sociedad. ${ }^{2}$ Es decir (entre otras cosas), un texto. Los antropólogos escribimos. ${ }^{3}$ Notas y diarios de campo, por supuesto, pero también el resultado de esa labor: tesis, libros, artículos. La redacción de monografías y tesinas es, sin ir más lejos, parte insoslayable de la finalización de una carrera académica en el ámbito local: no hay modo de obtener un título de grado en Antropología sin enfrentarse al texto escrito.

Es aquí - en el pasaje del campo al texto - donde vengo identificando desde hace un tiempo un cierto problema. En mi experiencia como docente e investigadora en distintos centros nacionales en el área de la antropología social (y la de muchos de mis colegas, a partir de las discusiones compartidas), me ha tocado presenciar las dificultades que genera en gran proporción de los estudiantes (mayormente de grado) la construcción del texto etnográfico, ya sea este una tesina o un paper. Desde luego, las dificultades varían según las lógicas particulares de cada texto, pero en todas parece repetirse un mismo grado de conflicto, relativo a la sobreiluminación de la investigación-como-campo por sobre la investigación-como-texto. Pareciera existir el supuesto de que el proceso de investigación se circunscribe al trabajo de campo y al armado, cuanto mucho, del marco teórico, y que el proceso de escritura es un simple "volcado 
de ideas", como si se tratara de una suerte de traducción inmediata y alcanzada sin esfuerzo de todo lo hecho en el campo. ${ }^{4}$

Si el primer momento alude, obviamente, al trabajo de campo y al material empírico que se va construyendo, el segundo tiene que ver con el modo en que convertimos todo ese material y esa vivencia en un escrito. Este modo implica, por un lado, la elección de un camino determinado entre la multiplicidad de caminos posibles: el recorte de una pregunta específica y una operación de armado del texto puesta en función de ella, de modo tal que el trabajo de campo - que es un corpus de datos enorme- logre acomodarse en función de ese interrogante construido como núcleo. Sabemos que la construcción de un texto antropológico es siempre un recorte, no solo espacial o temporal, sino principalmente analítico. Y que es, por ello, la construcción de una estrategia epistemológica: la elaboración de un curso de acción en función de una pregunta determinada.

Ambos momentos - la investigación-como-texto y la investigación-como-campoencierran objetivos distintivos. Y es por ello que la distancia entre ambos funciona de modo semejante al que plantea Wendy Belcher (2010) para el abogado y el detective: mientras este último recopila datos, junta información, acumula evidencia, el primero defiende un caso. Es decir, teje argumentaciones, elabora pistas, construye nexos y conclusiones. La problemática que guía a la investigación-como-campo nunca puede "traducirse", de modo lineal, en la pregunta (y su desarrollo) que ilumina la investigación-como-texto.

Y es en este tejer argumentaciones y construir nexos donde descansa el sentido último del pasaje del campo al texto, y la problemática de construcción textual que me interesa señalar de modo particular en este artículo. No porque sea de entre las muchas y variadas problemáticas posibles - necesariamente la más ardua, sino porque creo que es la que permite englobar mejor las dificultades de construcción textual que he venido identificando. Me refiero a la relación entre antropología y narrativa. Y no hablo aquí de narrativa en su sentido restringido de ficción, sino en un sentido tal vez más simple y primordial: en su acepción de decir. De escribir - como quería Cormac McCarthy - desplegando y eligiendo palabras.

Podría creerse que este eje puntual le queda grande a las problemáticas de construcción de un texto académico. Si entendemos que la acción de narrar - de contar, desplegar, desarrollar - se relaciona íntimamente con la construcción de lo empírico, entenderemos, sin embargo, que esta problemática condensa buena parte de las dificultades que los que somos docentes e investigadores venimos percibiendo en muchos de los alumnos (a partir de la evaluación de papers, de la corrección de monografías o de la dirección de tesis, por citar solo algunos ejemplos). Desde esta perspectiva, abordar la relación entre antropología y narratividad no es más que enfrentar las dificultades que conlleva la inscripción de la empiria en lo textual.

Porque construir un texto etnográfico implica, necesariamente, la presentación de este registro. Se ha dicho largamente: en parte para situarnos, como lectores, en la aldea que el investigador ha visitado; en parte también para convencernos de que este ha estado allí. Si lo empírico es el basamento sobre (y desde) el cual construimos los antropólogos nuestro análisis, lo narrativo se vuelve el recurso con el que contamos para aproximar ese campo a quienes nos leen. Para aproximar, si se quiere, cierta dosis de cercanía y credibilidad. Y no me refiero con esto a escribir bonito, sino a escribir adecuadamente: la comunicación
4. Entrevista a Fernando Alfón: "La tesis como escritura hermética”, en diario Página/12 (20 de junio de 2018) 
de nuestra experiencia de campo se sustenta grandemente en nuestra capacidad de construir, discursivamente, la justeza de eso que hemos experimentado (Díaz Viana, 1991). Desde este punto de vista, la narratividad no es otra cosa que la capacidad de describir y caracterizar, ya sean situaciones, actores, relaciones sociales o argumentos.

Etnografía y narración, entonces, son términos coimplicados. Este trabajo es un intento por resaltar esta vinculación, a partir de considerar dos de los obstáculos textuales que entraña la vinculación entre empiria y narratividad. El primero, el siempre difícil balance entre lo empírico y lo teórico a la hora de la construcción del conocimiento antropológico. El segundo, el papel que reservamos al trabajo de campo en los textos que escribimos. Se trata aquí de apuntar, respecto de estos obstáculos, algunas simples reflexiones, sobrevolando rápidamente por encima de argumentos y debates conocidos, para ir de lleno al planteo de situaciones. El objetivo es modesto y, en última instancia, pedagógico, pues apunta a hilar algunas pocas consideraciones en voz alta, con vistas a acercar, a nuestros estudiantes, un punteo esquemático pero concreto acerca de estas cuestiones. Lo que está en juego, en una panorámica de más largo alcance, es por supuesto la estimulación por una escritura académica que refleje toda la complejidad y la potencialidad de nuestros trabajos de campo, que reposicione la experiencia empírica analítica en el centro del proyecto antropológico (Sharman, 2007).

\section{II}

Me gustaría comenzar este apartado con el racconto de una experiencia personal. Hace unos años retomé mis estudios formales de dibujo. En las primeras clases ejercitamos la flexibilidad: el desafío era dibujar algo cinco veces - un pez, por ejemplo-, pero haciéndolo cada vez de modo distinto. Cinco versiones del mismo concepto. Después de décadas de no agarrar un lápiz por placer, fue una alegría asombrada ver que la mano se soltaba y era capaz de crear más allá de un solo pez prototípico.

Después vinieron las figuras en movimiento, los ejercicios de memoria visual y las pequeñas historias secuenciadas. Hasta que llegó la clase definitoria, a decir del profesor: aquella en la que se revelaban los verdaderos dibujantes. No verdaderos por sus "capacidades estéticas", es claro, sino por sus ganas de dibujar. La consigna era clara y parecía interminable: se trataba de dibujar una panorámica de ciudad. Esa primera vez, lo confieso, odié dibujar edificios al por mayor. Tres o cuatro clases después, al dibujar una historia que transcurría a lo largo de varios años, me descubrí disfrutando del hecho de navegar por Internet chequeando cómo era la ropa de los chicos de los años cuarenta o cómo lucían los patios de las casas de fines de los cincuenta. Disfruté aún más dibujándolos: poniendo esa ropa en un chico en particular, haciendo de ese patio construido a partir de mil imágenes sueltas el escenario de una acción.

Fue ahí que aprendí dos cosas. La primera, que un dibujo no es producto de una mano virtuosa, sino de un trabajo constante. Que la imagen no brota, impecable y acabada, de la punta de ningún lápiz, sino que se hace y se rehace innumerables veces. Que ningún dibujante es capaz de trazar, de la nada, el galope de un caballo sin antes haberlo estudiado. Que, en definitiva, un dibujo no es (salvo contadísimas excepciones) obra del genio espontáneo, sino un proceso de construcción: que antes de la imagen final hay borradores, pruebas, modelos, líneas descartadas, horas de documentarse. 
La segunda cosa que aprendí no fue estrictamente un aprendizaje sino la recuperación de una memoria: había olvidado que dibujar era tan parecido a escribir. Bocetando contextos - decidiendo cómo es la calle por la que camina el personaje que dibujo: el entramado de las baldosas o las puertas de las casas-, entendí que el escenario que se dibuja no es un mero fondo intrascendente sino parte central de la historia que ese dibujo narra. Casi otro personaje.

Si dibujar es contar con imágenes, dibujar escenarios es añadir a la caracterización de un suceso o de un personaje. Una historia - escrita o dibujada - no existe en un vacío empírico, sino en un mundo poblado de detalles que están ahí para darle a esa historia su color específico. Peinados batidos, casas bajas con frente de laja, las parras de los patios de otras épocas: esos detalles no son anécdotas, sino datos: marcas gráficas que sitúan a actores y eventos en un entramado social específico. Dibujar fondos, como quería mi profesor, me enseñó a narrar (si entendemos por dibujar el acto de obligarte a mirar detenidamente las cosas, y a usar eso que miraste para contar con imágenes).

La lección es igualmente válida para la narración escrita: si el dibujo enseña a narrar es porque enseña que el verdadero trabajo no consiste en explicar cosas, sino en mostrarlas. La máxima aplica al escrito académico, pues la narración no es ni más ni menos que un despliegue de lo empírico. Que es, al fin de cuentas, el tendido de un hilo argumentativo, en tanto se entienda al campo como sostén del análisis.

Y es acá, tal vez, donde en muchos de los textos que nos llegan como docentes e investigadores, se produce un primer cortocircuito. En un entendimiento restringido de la dinámica de construcción de conocimiento antropológico, que hace descansar el andamiaje del análisis en la única cadena de lo teórico. O mejor dicho, en lo teórico aislado de lo empírico, olvidando que la fortaleza de nuestro enfoque disciplinar implica la capacidad de construir teoría a partir de la reflexión empírica. En concordancia con esto, suele suceder que los estudiantes terminen sobredimensionando este registro teórico a la hora de construir sus textos. Que no se malentienda: no es esto un alegato en contra de lecturas y armazones conceptuales, sino un llamado de alerta respecto a su sobreutilización en el texto escrito. O mejor dicho: respecto de su desbalance en relación con la construcción del otro registro.

La sobredimensión de lo teórico ocurre, en estos textos, de dos modos básicos. Uno tiene que ver con la construcción de extensos recorridos conceptuales, con estados de la cuestión que desgranan datos y relaciones entre autores de modo tan extenso y detallado que el caso, cuando finalmente asoma en el texto, termina pareciendo un mero apéndice contingente y hasta tardío.

El otro modo es una variante del primero: el acorralamiento de lo empírico a manos de la profusión bibliográfica, donde pareciera que el campo propio no pudiera avanzar más que a resguardo de las citas de autoridad de los otros

Los informantes relatan una situación de mucha tensión, donde cuentan que los pibes de la otra cuadra habían pintado con consignas agresivas todo el frente de la salita.

El hecho fue visto negativamente, como un modo de "ensuciar" o "contaminar" un espacio recién pintado. De ahí que pueda ser visto como algo que puede resultar impuro para el entorno (de Certeau, 2009). Es también un modo de rebelarse frente a una figura de autoridad y desafiarla (Eamsley, 1998). 
5. Este, como los restantes extractos, corresponde a una monografía evaluada, cuyos datos fueron cambiados - con consentimiento del autor- para evitar la asociación directa con su trabajo de campo.
Sin embargo, aquí pareciera tratarse de un reclamo de "los pibes de la otra cuadra" por una aparente prerrogativa perdida, como lo es el uso de una calle y una esquina que era considerada propia. También podría ser visto como un castigo, un acto que busca marcar límites y decirle al otro quién se es, para reafirmarse a uno mismo (Connell, 2012).5

Ambas operaciones de escritura tienen que ver, tal vez, con un modo de desenvolverse propio de los comienzos del oficio: la inseguridad por la utilizacion de la voz propia, la inseguridad por un papel activo en el proceso de construcción de conocimiento. Pero no interesa acá rastrear causas, sino ponderar efectos. El producto de estas inseguridades apunta al agotamiento de lo empírico, en tanto alimentan párrafos de gran densidad conceptual que despachan el despliegue de este registro (las pintadas en el frente) en una o dos líneas.

En un sentido más inmediato, las operaciones reseñadas operan reduciendo el propio campo a una nota de color, al subsumirlo al estatus de ejemplo o de caso local de cara a una teoría de amplio espectro. En un sentido más general, y por supuesto relacionado, opera degradando lo empírico como fuente de saber: apostarse en una mirada confirmatoria puede llevar a pasar por alto los puntos de tensión posibles entre campo y teoría, obturando así la posibilidad de que este se convierta en un foco en sí mismo de producción de conocimiento.

La formación académica nos ha enseñado que las perspectivas etnográficas surgen a partir de construir el saber desde el interior hacia el exterior, y no de modo contrario. Que los argumentos deben generarse desde el campo, y no importarse desde el exterior. Sin embargo, la construcción de los textos antropológicos termina muchas veces operando de modo contrario: desarraigando la experiencia de campo e injertándola sobre el discurso académico, donde corre el riesgo de marchitarse demasiado fácilmente (Sharman, 2007; McGranahan, 2014).

Salir de este atolladero implica, creo yo, prestarle una atención más puntual al proceso narrativo. No se trata en este artículo de proponer estrategias narrativas concretas, sino de abogar por la posibilidad misma y general de esa narratividad. Señala Federico Lorenz que el oficio literario y el de historiador comparten una misma práctica: la escritura. Y que el historiador lo es "no (solamente) por analizar críticamente el pasado sino, sobre todo, por contar (y recoger) buenas historias" (2014, p. 31). Con las obvias variaciones disciplinares, similar afirmación le cabe también al oficio antropológico. Pero no porque persiga como fin último meras descripciones de campo, sino porque ese campo, para servir de insumo de conocimiento, precisa de construirse y desplegarse sabiamente en los textos.

Decía Flannery O'Connor que la ficción opera a través de los sentidos. Que ningún lector creerá nada de la historia que el autor narra, a menos que se le permita experimentar situaciones y sentimientos concretos. "La primera y más obvia característica de la ficción - detalla O'Connor - es que transmite de la realidad lo que puede ser visto, oído, olido, gustado y tocado". ${ }^{6}$ Lo mismo resalta Sharman de la antropología: "el arte etnográfico pasa por evocar las miradas, los sonidos, los olores, los sabores y la sensación de un lugar, conectando a la audiencia con los informantes a través del etnógrafo" (2007, p. 118).

Podría creerse que lo narrativo tiene solo que ver con el convencimiento. De la veracidad de una historia, como diría O' Connor. O de haber estado allí, como diría Geertz. Lograr ese convencimiento requiere, cómo no, de la escritura. 
De lograr transmitir, a partir de la composición del campo (descripciones, evocaciones, detalles, imágenes), cierto sentido de realidad. Pero conviene no cargar demasiado las tintas en la ligazón entre narratividad y convencimiento. Reducir lo narrativo a este eje (o leer este eje de modo ramplón) equivaldría a creer que despacharse narrativamente en un texto académico guarda visos de mero artilugio, casi de truco de magia, y que el modo en que el antropólogo acomoda sus ideas en el papel no es más que una fórmula mecánica y premeditada, destinada a la persuasión (siempre un poco embustera).

El papel de lo narrativo en un texto antropológico se anuda, creo yo, a una necesidad más básica y urgente. No busca solo convencer; busca antes mostrar. Un campo, un mapa de relaciones, una serie compleja de prácticas. Mostrar, no para explicar en líneas teóricas condensadas; mostrar como si se dibujara. Como si el campo, lejos de resolverse en unos pocos renglones - aplanado por la voz del investigador, que traduce sintetizando-, se desplegara, detalladamente, ante los ojos del lector. Mostrar ya no para persuadir, sino para acercar, para que lo dicho cobre vida: para invitar al lector a ver por sí mismo, para producir una experiencia narrativa donde ya no sea necesario, por ejemplo, que el investigador tenga que explicarle a ese lector lo que tal actor está sintiendo. El lector lo sabría: el trazado narrativo lo habría llevado hasta allí (Sharman, 2007; Beatty, 2010).

La diferencia es apreciable a simple vista: se trata, ni más ni menos, que de cerrar o abrir el campo. Volvamos al ejemplo de lo que siente una persona. Tomemos un extracto de campo:

La muerte de su amigo, a manos de la policía, lo atravesó de manera muy fuerte. El dolor, la bronca y la impotencia que sintió por su asesinato le permitieron darse cuenta de las situaciones de violencia y discriminación que habían vivido desde chicos en el barrio. Así, reconocer estas experiencias comunes de sujeción fue delimitando su participación en un grupo de activismo político.

Y contrastémoslo con el retrato que Barbara Myherhoff hace de Basha, una mujer mayor que asiste un centro de adultos mayores judíos en la Venice de principios de los años setenta:

Basha, sobre todo, quiere permanecer independiente. Su vida sola junto a la playa depende de su habilidad para desarrollar un número mínimo de tareas básicas. Debe hacer las compras y cocinar, vestirse, cuidar de su cuerpo y de su departamento de una habitación, caminar, tomar el bus hacia el mercado y el médico, ser capaz de hacer una llamada telefónica en caso de emergencia. Sus manos artríticas no la pasan bien con los botones de sus vestidos. Algunos días los dedos le duelen y se hinchan, a tal punto de que no entran en los agujeros del disco del teléfono. Sus manos tiemblan mientras se pone las gotas para el glaucoma. Afortunadamente, ya no tiene que auto-inyectarse para la diabetes. Ahora la controla con pastillas, si tiene el cuidado suficiente de medir lo que come (Myerhoff, 198o, pp.1-2, traducción propia).

Las diferencias entre uno y otro caso, creo, son notorias. El primer texto toma la escena - el dolor, la bronca, la impotencia -, pero la pasa automáticamente por encima. El hecho no sucede presencialmente, sino que a partir de una línea titular se asume todo. ${ }^{7}$ El texto de Myerhoff, en cambio, nos carga de imágenes. Nos dispara sensaciones y entendimientos que tal vez no se hubieran despertado de no ser por ese relato minucioso y empático que nos hace ser un poco Basha, al menos mientras leemos. El texto de Myerhoff nos permite palpar lo real.
7. Entrevista a Samanta Schweblin: "Alguien te está mirando", en diario Página/12 (11 de enero de 2019). 
Esa es la impronta de lo narrativo: no explicar, sino transportarnos allí. Hacernos vívido, experiencialmente, el mundo del otro (Quirós, 2014). La aproximación narrativa se vuelve, en tal sentido, una estrategia de escritura profundamente etnográfica.

Pero, ¿qué clase de escrito escribe el antropólogo? Es aquí donde surge una pregunta enteramente válida y que requiere de salvedades. Pues abogar por un despliegue mayor de lo narrativo en los dispositivos textuales de nuestra disciplina no implica nunca defender la existencia de una escritura etnográfica que se mueva dentro de las coordenadas de lo meramente descriptivo. El desarrollo argumentativo de las últimas páginas no debe impedirnos ver que, al igual que la excesiva teoricidad, la excesiva empiria es también un obstáculo frecuente en algunos escritos monográficos: La posibilidad de irse del pueblo era parte del horizonte de vida de los jóvenes de
su edad:

"Yo estoy esperando a terminar la secundaria para poder irme. Mi sueño es estudiar en Rosario. Mientras, trato de hacer changas en mi tiempo libre, cosa de ir juntando unos pesos. Ahora estoy esperando a ver si se vende un terrenito que tiene un tío de mi vieja, allá en el campo. Si lo vende bien, algo de plata le prometió a ella. Eso sería una pegada".

Las posibilidades de progreso de los jóvenes del pueblo depende muchas veces de estas “pegadas”. La situación económica no es buena para nadie, y tener plata para mantenerse afuera no es fácil. Las "changas" son casi la única solución en manos de estos jóvenes.

Todos nos hemos cruzado alguna vez con esos escritos, donde el ejemplo precedente se repite en su forma a lo largo de las páginas, logrando una construcción textual que, leída en su conjunto, abona un segundo cortocircuito en la relación textual entre empiria y teoría. Hay también aquí un entendimiento restringido respecto de cómo se construye el conocimiento antropológico: el campo gana una preponderancia tal (a veces una fascinación tal), que parece bastarse a sí mismo. El material empírico cobra completo protagonismo, pero en un sentido limitante: se transforma en un material de construcción único, que tanto pretende narrar como explicar, todo en un movimiento tautológico. El problema aquí no es que falte necesariamente teoría; es que falta análisis.

Que el análisis falte puede ser consecuencia, al menos en parte, de la mala interpretación de una muletilla del oficio: darles voz a los sujetos. Llevada al extremo, esta directriz no deja de producir una asociación bastante lineal entre antropología y descripción, al equiparar la transcripción de estas voces con el solo oficio del etnógrafo. Hablo específicamente de lo que sucede en el texto disciplinar: inscribir en ellos la voz de los sujetos -o su equivalente: la explicación del mundo en sus propios términos - termina confundiendo esos escritos con registros asépticos de campo, y haciendo por ende que la narratividad y la empiria se vuelvan insumos que basten y sobren para el sostenimiento de la construcción textual.

Proceder de este modo implicaría - yendo otra vez a los extremos - aquello que ya vaticinara Geertz: producir una interpretación de la forma en que vive un grupo que resultara prisionera de sus horizontes mentales, algo así como "una etnografía de la brujería escrita por una bruja" (1994, p. 75). El resultado no distaría mucho - para retomar los sugerentes contrapuntos 
disciplinares de Belcher, mencionados antes - de la acción de ir al psicólogo y de encontrarse con que este, a modo de devolución, solo repite lo que uno le dijo. Un texto antropológico -intento argumentar - lo es por no poder prescindir, justamente y en primer lugar, del análisis. Pero también por no poder prescindir de uno que suponga la mediación siempre interpretativa del etnógrafo.

Desde este punto de vista, es claro que la escritura antropológica no implica la construcción de cualquier narrativa, mucho menos de una narratividad genérica e inespecífica. Lo narrativo antropológico no apunta a la simple descripción de un evento, sino a una relación dialéctica: a un mostrar que sea deudor del ir y venir entre campo y teoría. A una manera de pintar la aldea ${ }^{8}$ que no agote sus fines en la mera persecución de una imagen de fidelidad fotográfica, sino en una capaz de tornar evidentes paletas, pinceladas, técnicas e intenciones; en una, finalmente, donde haya lugar tanto para la composición como para el artista (Daich y Varela, 2018).

Abogar por una mayor participación de lo narrativo en los textos antropológicos se vuelve entonces una empresa de contornos tan delicados como precisos. No implica, como espero haber demostrado, un mero reclamo por un mayor empiricismo-descriptivo o una mayor literatura, sino una invitación a una mayor experiencia empírica-analítica. Es decir, una invitación a que la textualización de nuestros campos gane en densidad fáctica sin caer en descriptivismos autoexplicativos.

Calibrar la justa importancia de esta empresa narrativa implica asumir entonces que la investigación académica es también, entre otras cosas, una operación de escritura. Que dicha escritura no es el mero vehículo con que se ofrecen los "resultados" de lo investigado, ni el paquete que uno ata a las apuradas una vez que termina esa investigación. Que el despliegue de la escritura es, por el contrario, el cuerpo mismo de la indagación. Y que conciliar antropología y proceso narrativo es, por ello, un intento por escribir de manera más justa y reflexiva, no para relajar la cientificidad de la investigación, sino para fortalecerla (Jablonka, 2016). Se dirá que nuestra disciplina obedece a exigencias de método. Por supuesto. Pero dentro de ese marco, como diría este autor, nada impide que el investigador escriba.

\section{III}

Pero la problemática que se anuda entre narratividad y texto académico no se agota en cómo se arregla, en ellos, el material de campo. Otro aspecto sobre el que me gustaría llamar la atención tiene que ver con el tratamiento (con la inclusión) del trabajo de campo mismo en los escritos que tratamos.

No se trata, por supuesto, de una línea de reflexión novedosa. El tópico viene analizándose desde hace décadas, al menos tangencialmente, para señalar un arco que parece comenzar en el realismo etnográfico de los antropólogos clásicos. El eje es aquí, como todos sabemos, el de la relación textual entre autoría y otredad, con un otro construido como homogéneo y generalizable, una etnografía que espeja la vida social y un antropólogo ausente - en tanto personaje- de la investigación escrita (con las justificadas excepciones de las palabras introductorias a la "investigación" en sí).
8. "Pinta tu aldea y pintarás el mundo". La frase se atribuye a León Tolstoi. 
Lo que subyace a este paradigma es, claramente, un posicionamiento epistemológico y político. $\mathrm{O}$, lo que es lo mismo, un entendimiento particular de aquello que es considerado apto - objetividad, neutralidad - para formar parte de la investigación-como-texto. Así, autoría etnográfica y presencia del investigador en el texto no son más que emergentes puntuales de una particular manera de concebir un escrito antropológico legítimo. Es decir, de cribar lo que debe o no pasar del campo a la letra impresa.

Las reacciones que suscitó, en el mundillo académico, allá lejos y hace tiempo, la publicación de los diarios de Bronislaw Malinowski, es buen ejemplo de esto. Se recordará la introducción que Raymond Firth escribiera para su reedición, en la que revisa la incomodidad y vergüenza que le había causado tener que escribir la primera:

Lo que tendí a pasar por alto en la Introducción original fue el valor de los Diarios en un sentido analógico [...] La moda contemporánea por la "antropología reflexiva" parece a veces volver la etnografía en autobiografía. Pero hay un reconocimiento más claro, actualmente, acerca de que la posición de un etnógrafo no es solamente la de un registrador de la vida de una sociedad, sino que es también la de alguien que tanto afecta esa vida y es afectado por ella [...].

La relativa falta de información sobre las reacciones personales de los tempranos antropólogos en el campo tendieron a dar un aire de olímpica distancia en relación con los informes publicados: el antropólogo llegó, vio, registró y se retiró para pasar en limpio el material, aparentemente no tocado por sus experiencias, con, a lo sumo, un capítulo introductorio con comentarios sobre la relación con la gente y su efecto sobre el trabajador de campo. Con la publicación de los Diarios de Malinowski este estereotipo se destruyó (Firth, 1989, pp. xxi-xxxi, traducción propia).

La introducción de Firth que acompaña a la publicación original de los diarios es de 1966. La segunda, correspondiente a la reimpresión, es ya de 1988. La moda de la antropología reflexiva, según su decir, había cambiado, de una introducción a otra, el signo de los tiempos. Lo que se había expandido - también según sus palabras - era el concepto mismo de etnografía. Si en la primera introducción Firth dejaba traslucir un cierto regusto escandalizado por la irrupción de la agenda "personal" en el texto académico, en la segunda comenzaba a preguntarse por la validez de una pregunta: ¿qué lugar hay para el yo del investigador (y para qué clase de yo) en la etnografía escrita? La apuesta contemporánea parecía habilitar esta pregunta, pues no solo se trataba de rescatar la gravitación de la subjetividad del antropólogo en el proceso de investigación, sino también de dejar de silenciar su contorno en las investigaciones que escribimos.

De lo que se trataba, en última instancia, en esa expansión de la etnografía, era de dejar de leer el trabajo de campo en función de efectos compartimentados: de este lado el producto cognitivo (el texto científico), de este otro las tribulaciones personales (diarios, cartas); de un lado el campo-como-dato (la información cualitativa "dignificada" al tamiz de las convenciones académicas), del otro el campo-como-anécdota (la masa burda de empiria incapaz de tomar una forma científicamente jerarquizada).

A nadie escapa que todas estas consideraciones pertenecen al pasado, y que los textos antropológicos de hoy ya no reconocen estas distinciones. Tiendo a creer, sin embargo, que este proceso está lejos aún de completarse. Porque, a pesar de que, ciertamente - como señala Julieta Quirós - , muchos colegas ensayan 
estrategias narrativas que apuestan a análisis vívidos del mundo social, estas estrategias no hacen al lenguaje de la antropología media que escuchamos en mesas de trabajo o leemos en tesinas (2014, p. 58). Seguimos asistiendo, en muchos de estos casos, a textos que, aun cuando comercian con el material empírico como lo hacen, siguen sin abordar, necesaria y completamente, el proceso en sí de ese trabajo de campo. Es decir, del trabajo de campo como verdadero protagonista de la configuración textual: de la inclusión en nuestros escritos de la trama misma - los vínculos, las prácticas, las marchas, los rechazos- con que se fue conformando la investigación-como-campo.

Es probable que la diferencia entre una y otra postura quede mejor evidenciada en los siguientes ejemplos. Tomemos en primer lugar la conferencia que Jean Briggs diera, en 1995, en Memorial University, donde revisita su estadía de campo en el campamento Inuit de Gjoa Haven durante los años que van de 1963 a 1965 (y que fuera publicada cinco años después en una revista académica):

Una idea central de la educación Inuit es "causar el pensamiento". Los adultos estimulan a los niños a pensar presentándoles problemas poderosamente emocionales, que los niños no pueden ignorar. Una forma de hacer esto es hacer una pregunta que tiene el potencial de ser peligrosa para el niño siendo cuestionado y dramatizar las consecuencias de las diferentes respuestas [...].

Una niña de tres años ... estaba sentada en mi falda, jugando con mi nariz y con los lápices en mi bolsillo. Su madre le preguntó: “¿consideras que Yiini es buena?”. Maata levantó sus cejas: "sí”. Madre: “isí? ¿Sabes que ella es una qallunaaq? ¿Sabes que los qallunaaq reprenden? ¿Sabes que ella se va a ir muy lejos, a su país? ¿Quieres ir con ella?". Chubby Maata comenzó a mirarme solemne e inquisitivamente. Madre: “¿crees que Yiini es buena?”. Maata arrugó su nariz: "no”. Madre, con un tono de sorpresa: "¿no? ¿Crees que no te nallik-? ¿Quién te da té? ¿Quién te da pan yjamón? ... ¿Crees que es buena?". Maata: "no". Su madre se rió (Brigss, 2000, pp. 161-162, traducción propia).

Pasemos ahora a un texto anterior de la autora: Never in Anger, la etnografía producto del trabajo de campo mencionado, publicada en 1970:

Algunos días pasaron, sin embargo, antes de que me diera cuenta de que había sido aislada. Mi trabajo me parecía, de algún modo, más difícil que de costumbre, me sentía cansada y deprimida; "molida". Tal vez, pensé, necesitaba vacaciones [...] Ahora que los hombres se habían ido, pasaba un montón de tiempo sola en mi tienda, pasando notas a máquina, escribiendo cartas y tratando de analizar mis datos lingüísticos. Sentía pocos deseos de compañía y me sentía agradecida de que las caras sonrientes que aparecían de tanto en tanto en la entrada de mi tienda se hubieran retirado sin entrar. No percibí nada inusual en el comportamiento de ninguno de ellos hacia mí.

Me di cuenta de repente y de una manera inesperada [...] Sabiendo que el avión escolar podía llegar en cualquier momento, escribí una carta tras otra [...].

Pala también escribió una carta... y, sonriendo cálidamente, me la dio para que se la guardara hasta que llegase el avión. "Así no me olvido de enviarla", me dijo. La carta estaba en silábico, por supuesto, y movida por no sé qué espíritu amoral, decidí leerla - para testear mi habilidad en leer Eskimo ... Comenzaba, más o menos como era de esperar, describiendo la recompensa de los kapluna y cuánto habían 
9. No se trata acá de sugerir que el trabajo de campo inscrito en el texto sea un calco inocente del trabajo de campo en sí (ningún mapa es un territorio, como nos enseñó el cuento de Borges). Todo texto implica una construcción, pero una cosa es que la haya del proceso recorrido y otra del dato suelto. ayudado estos a los Eskimo. Luego continuaba en un tono que no había anticipado: "Yiini es una mentirosa. Le mintió a los kapluna. Se enoja (ningaq) muy fácilmente. Es fastidiosa (urulu), porque regaña (huaq) y uno se siente tentado de regañarla. Se enoja fácilmente. Dado que es tan fastidiosa, deseamos cada vez más que se vaya".

Escrudiñé las sílabas crueles por algún tiempo, deseosa de no estar leyéndolas correctamente. Tal vez estaba insertando las consonantes equivocadas al final de las sílabas; el texto no las suministraba. Pero no estaba equivocada. Había solo una manera de leer los caracteres. ¡Así que había una razón por la cual mi trabajo había andado malamente! Y mi depresión no se debía para nada al fatigoso verano. Lo que más me impactó fue que, al mirar atrás hacia los diez días desde que había hablado con el guía kapluna, no era capaz de identificar ningún cambio en el comportamiento habitualmente cálido, amistoso y considerado de los Utku (Briggs, 1970, pp. 285-286, traducción propia).

Se trata, este último texto, de una etnografía pionera. Y no solo por el estudio de la emoción y la reflexión acerca de la propia emocionalidad de la etnógrafa en el proceso de investigación, sino por ser una pieza que, en tanto escapa un poco a las convenciones de un registro académico ortodoxo, nos permite atisbar el camino de los obstáculos, aciertos y decisiones empíricas que fueron haciendo posible su investigación. En esta, el trabajo de campo cobra preponderancia en tanto ruta: su derrotero está contenido por entero en el texto. ${ }^{9}$ Algo diferente sucede en el primer caso - el de la transcripción de la conferencia - , donde el campo aparece ya no como proceso sino como cantera: como espacio que solo se vuelve visible, y de modo fragmentario, a partir de las piedras (los datos) que de él extraemos para exhibir en el texto.

Recuperar el trabajo de campo en el texto antropológico académico es justamente la apuesta - tanto epistemológica como narrativa- que me interesa enfatizar en este apartado. Esto es, recuperar la posibilidad de que el trabajo de campo - no solo el campo-como-dato sino el campo-como-proceso- se vuelva un insumo legítimo en las etnografías que escribimos. De lo que se trata es, en definitiva, de recuperar toda la riqueza que encierra la marca distintiva de nuestra disciplina.

Porque el trabajo de campo es, extrañamente, una instancia sobre la que solemos vanagloriarnos a la hora de trazar coordenadas epistemológicas, pero de la que solemos escribir poco y nada. El trabajo de campo pareciera no ser merecedor, como diría Rosana Guber (2017), de convertirse en cuestión y objeto de nuestras elucubraciones teóricas. Nos sirve para tomarlo como instancia de producción de datos, pero no para permitirnos reflexionar acerca de sus desafíos. Al no analizar conceptualmente en el texto las instancias propias del trabajo de campo - continúa la autora - , la empiria se transforma en un "dato pelado", plantado allí de manera autónoma y recortada, como si ese dato tuviera un sentido transparente y propio al que se pudiera acceder sin contexto ni situación (Guber, 2017).

La apuesta es entonces, decía, epistemológica, pues implica valorizar el proceso de trabajo de campo tanto en la formulación de nuestras investigaciones como en sus resultados escritos. Mirar de cerca los modos en que escribimos antropología se vuelve necesario para nivelar procesos de escritura y procesos investigativos, haciendo que la construcción de un texto disciplinar pueda acercarse a toda la riqueza y todo el potencial que esconde la práctica de nuestro oficio. Que no se malentienda: no se trata de abogar por la necesidad 
de una mejor escritura, sino por la necesidad de una escritura antropológica más fiel al trabajo de campo del que proviene.

Pero la apuesta es también, por todo esto, narrativa. En 1972, la revista American Anthropologist publicaba una reseña de la etnografía de Jean Briggs:

Desafortunadamente, en su forma actual, los datos no están ni suficientemente sistematizados ni analizados para ser valiosos con vistas a un objetivo comparativo, ni proveen el marco coherente para comprender la vida emocional de los esquimales. Desde esta perspectiva, la obra es difícil y a menudo frustrante de leer. Sin embargo, si uno elige desde el principio leerla de modo diferente, como uno pudiera leer una novela, es fascinante, informativa y muy humana... El estilo narrativo, que es inadecuado para la descripción cultural y la generalización, puede ser un insumo delicado para expresar, a nivel visceral, lo que significa un trabajo de campo largo y difícil para todas las partes involucradas (Gussow, 1972, p. 871, traducción propia).

La reseña puede fácilmente leerse como el relato de una indignación. Allí donde hay un trabajo fundacional, Gussow ve un trabajo fallido. La ecuación es clara: una pluma en primera persona, con la investigadora habitando vívidamente las páginas de la etnografía, no puede parecerle más que una novela. El estilo narrativo elegido por la autora la hace para siempre una obra inadecuada para su género. Adolece de cientificidad: no hay en ella datos que puedan sistematizarse ni generalizarse. Es, cuanto mucho, el racconto visceral10 que permite dar cuenta de las vicisitudes de un trabajo de campo. Es decir, la escritura de una obra menor.

Cuarenta y dos años después de la publicación de Never in Anger, el historiador Ivan Jablonka daba luz a un libro que sería profusamente aclamado justamente por aquello que se le había criticado al de Briggs. Historia de los abuelos que no tuve es, a la vez que una investigación, "una biografía familiar": una obra que une el archivo riguroso con la reconstrucción flexible, una prolongación del trabajo de historiador del autor, acometido para investigar y narrar - las dos empresas al unísono - la historia de los abuelos paternos a los que nunca conoció, muertos en campos de concentración durante el nazismo:

Partí, como historiador, tras las huellas de los abuelos que no tuve. Sus vidas se terminan mucho antes de que la mía comience: Mates e Idesa Jablonka son tan parientes míos como absolutos desconocidos. No son famosos. Se los llevaron las tragedias del siglo XX: el estalinismo, la Segunda Guerra Mundial, la destrucción del judaísmo europeo (Jablonka, 2015, p. 12).

Este es el comienzo. Lo que sigue son más de trescientas páginas del relato de un derrotero. Del peregrinar de sus abuelos, desde el shtetl polaco de origen hasta el final en los campos de concentración. Pero también del suyo propio, como nieto e historiador, buscando desandar esos pasos: siguiéndolos a través de las fuentes existentes, imaginándolos a través de experiencias similares, echándolos en falta en las lagunas de la historia. Jablonka podría haber escrito un libro "depurado": uno donde la materia prima quedara oculta bajo la tersa prosa de la historia, donde apenas se distinguiese esa base, ese proceso (Caimari, 2017). Eligió, en cambio, un camino infinitamente más rico: un cruce que reuniera aquello que en el siglo XIX había sido separado - ciencias sociales y bellas letras - y que le permitiera desplegar, una a una, las rugosidades de la investigación. El desafío era claro: discutir el falso postulado de que las ciencias sociales no tienen una dimensión "literaria", y que, de tenerla, no por ello pierden "cientificidad" (Jablonka, 2016, p. 11).
10. Que la etnografía fuera un estudio de las emociones ilongot de seguro ayudaba a la pátina de sospecha. El estudio de las emociones por parte de las ciencias sociales solo termina de legitimarse en Estados Unidos en la década del ochenta. La literatura es profusa el respecto; para un mapa de ruta por ella, ver Sirimarco y Spivak L'Hoste (2018). 
Porque al fin de cuentas, lo que importa en el texto de Jablonka - así como en el de Briggs - es que la riqueza de lo encontrado no termine convirtiéndose en un mero reporte de datos, ni que las vivencias que conducen a ellos queden aplanadas por el despliegue de los hechos rasos. Lo que importa, en estas obras, es plantear un problema que tanto pueda ser analizado como contado. Evitar el recuento frío de "los hechos" se vuelve entonces, me parece, un modo de hacerle justicia a la experiencia (Sirimarco, 2016).

Y acá es donde entra a jugar lo narrativo. Pues la inclusión del proceso de trabajo de campo en nuestros textos implica animarse a prescindir de cánones de escritura académica más encorsetados. Esto es, animarse a habilitar como zona narrable los pasos que terminan dando forma al camino de una investigación. No solo para rescatar la infinita largura que conlleva la construcción de un dato, sino para componer un texto que sea fiel al carácter siempre subjetivo de su producción y que no pierda de vista que el racconto de una investigación es siempre la narración de un suceso visto por alguien (Sirimarco, 2016). Se trata, en otras palabras, de lograr que la importancia del recorrido no sucumba ante la premura del resultado. De generar un texto etnográfico en su sentido más profundo: un texto que no sea impermeable a la experiencia de haber estado allí.

Se trata, por ende, de darle lugar, no al regodeo autorreferencial, sino al narrador situado. La diferencia es abismal: lo que se ilumina, en este camino narrativo, no es el investigador en sí mismo, sino el proceso del encuentro etnográfico (Tedlock, 1991). Porque después de todo, como señala Renato Rosaldo (2011), la narrativa siempre ha existido dentro de la etnografía. El tema es que lo ha hecho de modo marginal, bajo el formato siempre menor de las introducciones a los libros, las notas a pie de página o los casos de estudio.

Este trabajo ha intentado argumentar así la necesidad de reunir aquellos registros que por mucho tiempo fueron vistos como entidades separadas narrativa y análisis etnográfico-, no con ansias literarias o ficcionales, sino con fines perfectamente científicos: se trata, en última instancia, de aprovechar de modo máximo las posibilidades analíticas de lo empírico, para construir textos que verdaderamente reflejen el contexto de producción de nuestro conocimiento. O lo que es lo mismo, de hacer de lo narrativo antropológico el motor real de los textos que escribimos.

\section{Sobre la autora}

Mariana Sirimarco es Doctora de la Universidad de Buenos Aires en Ciencias Antropológicas, Investigadora Independiente del CONICET. 


\section{Q Referencias bibliográficas}

" Beatty, A. (2010). How did it feel yor fou? Emotion, narrative and the limits of ethnography, American Anthropologist, 112(3), 430-443.

" Belcher, W-L. (2010). Cómo escribir un artículo académico en 12 semanas. Guía para publicar con éxito. México: Flacso.

" Briggs, J. (1970). Never in anger. Portrait of an Eskimo family. Cambridge: Harvard University Press.

》 Briggs, J. (2000). Emotions have many faces: Inuit lessons. Anthropologica, 42(2), 161-162.

"Caimari, L. (2017). La vida en el archivo. Goces, tedios y desvíos en el oficio de la historia. Buenos Aires: Siglo XXI.

"Cardoso de Oliveira, R. (2000). O Trabalho do antropólogo. Brasilia: São Paulo Editora UNESP.

"Daich, D. y Varela, C. (2018). Antropólogas feministas en las intrincadas aldeas del sexo comercial. En K. Tinat y R. Parrini (Comps.). Etnografias de la sexualidad en América Latina (en prensa). México: El Colegio de México.

" Díaz Viana, L. (1991). Prólogo a la edición española. En J. Clifford y G. Marcus (Eds.). Retóricas de la Antropología (s.p.). Madrid: Júcar Universidad.

" Firth, R. (1989). Second introduction 1988. En A diary in the strict sense of the term (pp. xxi-xxi). Stanford: Stanford University Press.

» Geertz, C. (1986). La interpretación de las culturas. Barcelona: Gedisa.

» Geertz, C. (1994). Conocimiento local. Ensayos sobre la interpretación de las culturas. Buenos Aires: Paidós.

" Guber, R. (2017). Conocimiento antropológico, trabajo de campo y patetismo editorial. Cuestión de escala y de tiempo. Recuperado de https://www.wcaanet.org/publications/ propios_terminos/guber.shtml

》 Gussow, Z. (1972). Never in Anger. Review. American Anthropologist, 74(4), 871-872.

"Jablonka, I. (2015). Historia de los abuelos que no tuve. Buenos Aires: Libros del Zorzal.

" Jablonka, I. (2016). La historia es una literatura contemporánea. Manifiesto por las ciencias sociales. Buenos Aires: Fondo de Cultura Económica.

"Lorenz, F. (2014). Los zapatos que calzamos. De la novela como revancha del historiador. Anuario Digital, 26, 29-45.

" Marcus, G. (1991). Epílogo: la escritura etnográfica y la carrera antropológica. En J. Clifford J. y G. Marcus (Eds.). Retóricas de la Antropología (s.p.). Madrid: Júcar Universidad.

" McGranahan, C. (2014). What is Ethnography? Teaching Ethnographic Sensibilities without Fieldwork, Teaching Anthropology, 4, 23-36.

" Myerhoff, B. (1980). Number our days. Nueva York: First Touchstone Edition.

》Quirós, J. (2014). Etnografiar mundos vívidos. Desafíos de trabajo de campo, escritura y enseñanza en Antropología, Publicar, XII(XVII), 47-65.

》 Reynoso, C. (Comp.). (1991). El surgimiento de la Antropología posmoderna. México: Gedisa. 
" Rosaldo, R. (2011). La narrativa en la etnografía: el imaginario asimétrico, el punto de vista y la desigualdad. En A. Grimson, S. Merenson y G. Noel (Comps.). Antropología ahora. Debates sobre la alteridad (pp. 61-68). Buenos Aires: Siglo XXI.

» Sharman, R. L. (2007). Style matters: ethnography as method and genre. Anthropology and Humanism, 32(2), 117-129.

» Sirimarco, M. (2016). El último Chonino. Crónica de una investigación sobre policía y heroísmo. Buenos Aires: Antropofagia.

» Sirimarco, M. y Spivak L’Hoste, A. (2018). Introducción: la emoción como herramienta analítica en la investigación antropológica. Etnografías Contemporáneas, 4(7), 7-15.

» Tedlock, B. (1991). From participant observation to the observation of participation: the emergence of narrative ethnography. Journal of Anthropological Research, 47(1), 69-94. 